\title{
Molar incisor hypomineralization (MIH): conservative treatment management to restore affected teeth
}

\section{Camila Maria Bullio FRAGELLI(a) Juliana Feltrin de SOUZA ${ }^{(b)}$ \\ Fabiano JEREMIAS ${ }^{(a)}$ \\ Rita de Cássia Loiola CORDEIRO(a) Lourdes SANTOS-PINTO(a)}

(a) Universidade Estadual Paulista - UNESP, Araraquara School of Dentistry, Department of Pediatric Dentistry and Orthodontics, Araraquara, SP, Brazil.

(b) Universidade Positivo - UP, School of Dentistry, Department of Pediatric Dentistry, Curitiba, PR, Brazil.

Declaration of Interests: The authors certify that they have no commercial or associative interest that represents a conflict of interest in connection with the manuscript.

\section{Corresponding Author:}

Lourdes Santos-Pinto

E-mail: Ispinto@foar.unesp.br

DOI: 10.1590/1807-3107BOR-2015.vol29.0076

Submitted: Oct 01, 2014

Accepted for publication: Feb 20, 2015

Last revision: May 14, 2015

\begin{abstract}
The purpose of this study was to evaluate the 12-month clinical performance of glass ionomer restorations in teeth with $\mathrm{MIH}$. First permanent molars affected by MIH (48) were restored with glass ionomer cement (GIC) and evaluated at baseline, at 6 and at 12 months, by assessing tooth enamel breakdown, GIC breakdown and caries lesion associations. The data were analyzed using the chi-square test and actuarial survival analysis. The likelihood of a restored tooth remaining unchanged at the end of 12 months was $78 \%$. No statistically significant difference was observed in the association between increased MIH severity and caries at baseline $(p>0.05)$ for a 6-month period, or between increased MIH severity and previous unsatisfactory treatment at baseline $(p>0.05)$ for both a 6 - and 12-month period. A statistically significant difference was observed in the association between increased $\mathrm{MIH}$ severity and extension of the restoration, involving 2 or more surfaces $(\mathrm{p}<0.05)$ at both periods, and between increased MIH severity and caries at baseline $(p<0.05)$ at a 12-month period. Because the likelihood of maintaining the tooth structures with GIC restorations is high, invasive treatment should be postponed until the child is sufficiently mature to cooperate with the treatment, mainly of teeth affected on just one face.
\end{abstract}

Keywords: Tooth Demineralization; Child; Longitudinal Studies.

\section{Introduction}

Molar incisor hypomineralization (MIH) was defined in 2001 as a qualitative enamel defect of systemic origin. It affects from 1 to 4 of first permanent molars and can also be associated with permanent incisors. ${ }^{1}$ The etiology remains unknown, but recent studies simulating the same types of spots in rats exposed to Bysfenol $\mathrm{A}^{2}$ indicate that the insult occurs in children about 7 months old, ${ }^{3}$ presents genetic involvement, ${ }^{4,5}$ and suggests a link between MIH and health problems during pregnancy, and also environmental factors. ${ }^{6}$

The world prevalence of MIH ranges from $2.4 \%$ to $40 \% 7$. Clinically, hypomineralized enamel presents as a white to yellow or brown porous opacity, ${ }^{8}$ with borders that are well-defined and distinct from healthy enamel. ${ }^{9}$ At times, the opacity is so porous that the teeth may break immediately after eruption, leaving the dentin exposed and enabling dental caries lesions to develop. ${ }^{10,11,12}$ Teeth affected by MIH have a high 
degree of porosity, extending to the amelodentinal junction..$^{13}$ The yellow and brown opacities present as microscopically porous, ${ }^{9}$ with a higher clinical risk of breakdown than that of the white opacities. ${ }^{14}$

Treatment includes preventive procedures indicated only in cases where there is no structural tooth loss, or else conservative or invasive restorations with removal of the affected area. ${ }^{15}$ However, there is no scientific substantiation for complete or premature removal of the affected area. ${ }^{16,17,18}$

Based on the above considerations, the purpose of this longitudinal study was to evaluate the clinical performance of glass ionomer restorations in teeth with MIH for a period of 12 months.

\section{Methodology}

This study was approved by the Research Ethics Committee of the Araraquara Dental School, São Paulo, Brazil (protocol \#41/09), and was conducted after the parents or guardians of the children provided their written, free and clarified consent.

\section{Subjects}

This prospective cohort study included 21 children, 6 to 9 years of age, diagnosed with MIH at the Pediatric Dentistry Clinic of the Araraquara Dental School in São Paulo, Brazil. More specifically, it studied 48 of their first permanent molars affected by unsatisfactory atypical restorations and post eruptive breakdown, and associated with or without caries.

The participants in this study were selected from a previous epidemiological survey composed of 1,157 children, with $12.3 \% \mathrm{MIH}$ prevalence. The children diagnosed with $\mathrm{MIH}$ and presenting the inclusion criteria were invited to participate. ${ }^{19}$

\section{Treatment}

All the patients in this research received weekly applications of $5 \%$ fluoride varnish (Duraphat ${ }^{\circledR}$ Colgate, New York, USA), over a one-month period, as well as oral hygiene instructions. The teeth affected by MIH with structural loss but without tooth decay were restored with GIC (Ketac Molar Easymix, 3M ESPE, São Paulo, Brazil), under absolute isolation, without removal of the area affected by MIH. The teeth with structural loss and caries lesion, or non-satisfactory atypical restorations, were also restored with GIC, under absolute isolation, after the decayed tissue or the deficient restoration was removed by low or high rotation, respectively. The tissue affected by opacities without caries lesion was preserved. The glass ionomer restoration was referred to as an "atypical protective restoration". All teeth that received restorative material were sufficiently erupted to undergo absolute isolation. The same dentist operating under the same conditions and using material from the same lot performed the restorations.

After all the teeth were restored, they were photographed, and impressions were taken using silicone condensation trays (Zetaplus System, Zhermack, Badia Polesine, Italy). The molds were cast with special stone models (Durone IV, Dentsply, Petrópolis, Brazil), to document and compare the integrity of the restorations in subsequent evaluations.

\section{Evaluation}

The clinical exams were performed in a clinical environment, with mouth mirrors recommended by the World Health Organization, ${ }^{20}$ under artificial light, and subsequent to cleaning and drying with sterile gauze. A blinded and calibrated examiner clinically evaluated the restoration at baseline, six and twelve months.

\section{Calibration and reproducibility}

The examiner was calibrated according to the DMFT index criteria for tooth decay. ${ }^{20}$ The scores indicating "Treatment needs for individual teeth", ${ }^{20}$ established by WHO criteria, were employed to determine if treatment was required. MIH diagnosis was based on criteria proposed by the European Academy of Pediatric Dentistry (EAPD) ${ }^{10}$ The examiner evaluated 32 clinical photographs of patients from the Pediatric Dentistry Clinic of the Araraquara Dental School in São Paulo, Brazil. A discussion with the MIH research team followed to establish all the indexes, codes and criteria to be used. After reaching an agreement, 30 patients presenting with enamel alterations (17 from $\mathrm{MIH}$ ) were evaluated. These patients were not included in the research. After 2 weeks, the patients were evaluated again, and the Kappa index was used to verify the agreement 
between the evaluations. The gold standard was an experienced examiner. The intra-administrator values for tooth decay and for MIH were greater than 0.91 .

The MIH severity of each tooth was graded at baseline, according to the most severe defect of the tooth surface. The structural loss and the presence of non-satisfactory atypical restorations were noted, in that the latter was more severe.

The extent of tooth caries was determined by the presence of tooth-decayed surfaces (DMFT index). The need for treatment was defined by the presence of one and two or else more surfaces in need of rehabilitation. Sealant treatments and preventive care were not considered as criteria for needing treatment. Teeth requiring endodontic treatment and extraction were excluded.

An increase in MIH severity in teeth with atypical protective restorations was defined as the presence of tooth surface breakdown or restorative material failure.

The restorations were evaluated according to the restoration quality criteria proposed by the United States Public Health Service USPHS-Modified, ${ }^{21}$ and were classified as satisfactory or unsatisfactory, according to Table 1 . When a restoration failure was observed, new molds were made and photographs were taken to determine the location and extent of the breakdown, as follows: limited to the material only, limited to the tooth surface only, or extending to both material and tooth surface. The findings were then compared with the baseline. When the tooth restoration was considered unsatisfactory, the restoration was replaced and the tooth was excluded from the study.

\section{Statistical analysis}

The data were analyzed using the Statistical Package for Social Sciences computer program, version 16.0 for Windows (SPSS Inc., Chicago, USA). Descriptive statistics were used to present the results. Associations between the categorical variables were assessed using Fisher's exact test at a significance level of $5 \%$, and relative risk (95\%CI). Survival of the $\mathrm{MIH}$ restorations was evaluated by the technique of actuarial methods.

\section{Results}

The average age of the participants was 7.7 years old (6.37 -9.54), and $57.1 \%$ of the sample was male. Of the 48 molars included in this study, $69.3 \%$ had structural tooth loss and $30.7 \%$ presented unsatisfactory atypical restorations at baseline. MIH severity changed during the period studied, due to the breakdown of protective restorations. Failure was recorded in four restorations after

Table 1. United States Public Health Service USPHS-Modified classification as:

\begin{tabular}{|c|c|c|}
\hline \multicolumn{3}{|c|}{$\square$ satisfactory or $\square$ unsatisfactory } \\
\hline \multirow[t]{3}{*}{ Anatomic Form } & Alfa & Continuous \\
\hline & Bravo & Slight discontinuity, clinically acceptable \\
\hline & Charlie & Discontinuous, failure \\
\hline \multirow[t]{3}{*}{ Marginal Adaptation } & Alfa & Closely adapted, no visible crevice \\
\hline & Bravo & Visible crevice, explorer will penetrate \\
\hline & Charlie & Crevice in which dentin is exposed \\
\hline \multirow[t]{3}{*}{ Surface Texture } & Alfa & Enamel-like surface \\
\hline & Bravo & Surface rougher than enamel, clinically acceptable \\
\hline & Charlie & Surface unacceptably rough \\
\hline \multirow[t]{3}{*}{ Marginal Discoloration } & Alfa & No discoloration \\
\hline & Bravo & Discoloration without penetration in pulpal direction \\
\hline & Charlie & Discoloration with penetration in pulpal direction \\
\hline \multirow[t]{2}{*}{ Retention } & Alfa & No loss of restorative material \\
\hline & Charlie & No loss of restorative material \\
\hline \multirow[t]{2}{*}{ Secondary Caries } & Alfa & No caries present \\
\hline & Charlie & Caries present \\
\hline
\end{tabular}


6 months, and six teeth had restoration failure at 12 months. The cast molds and photographic evaluations evidenced that 2 restored teeth $(20 \%)$ restorative material loss, whereas 8 restored teeth $(80 \%)$ had restorative material loss associated with tooth structure breakdown. The likelihood of a restored tooth remaining unchanged at the end of 12 months was $78 \%$ (Table 2).

No statistically significant difference was observed in the association between increased MIH severity and caries at baseline $(\mathrm{p}>0.05)$ for a 6 month period, or between increased MIH severity and previous unsatisfactory treatment at baseline $(p>0.05)$ for both a 6- and 12-month period.

A statistically significant difference was observed in the association between increased MIH severity and extension of the restoration, involving 2 or more surfaces $(p<0.05)$ at both periods (Figures 1 and 2$)$, and between increased MIH severity and caries at baseline $(\mathrm{p}<0.05)$, for a 12 -month period (Table 3$)$. Eight of the 10 teeth had caries associated with a failed restoration.

\section{Discussion}

MIH-type enamel alterations pose a great challenge to all dentists. Longitudinal studies on the clinical performance of restorations of affected teeth are extremely important in backing up decisions regarding treatment. Studies to evaluate the restorations in $\mathrm{MIH}$-affected teeth are rare. This is what motivated this study, designed to obtain higher quality clinical findings and descriptions of restored MIH teeth, through clinical examinations, photographs and cast molds.

All of the 48 molars affected by MIH received GIC restorations and only 10 teeth presented restoration failure during the observed period, $80 \%$ due to material loss and tooth structure breakdown and, 8 cases of restoration failure associated with caries.

Given the uncertain prognosis and susceptibility to caries, patients with MIH require special attention, and present with 10 times more need of treatment than patients without the condition, ${ }^{22}$ even those patients with low caries activity. ${ }^{23}$ Early diagnosis is essential, in conjunction with the use of preventive or curative treatment, because of the rapid breakdown

Table 2. Actuarial methods for assessing protective restoration

\begin{tabular}{lccccccc}
\hline $\begin{array}{l}\text { Interval } \\
\text { (months) }(x)\end{array}$ & $\begin{array}{c}\text { Subjects alive at } \\
\text { start of interval }\left(l_{x}\right)\end{array}$ & $\begin{array}{c}\text { Subjects withdrawing } \\
\text { during the interval }\left(w_{x}\right)\end{array}$ & $\begin{array}{c}\text { Subjects at } \\
\text { risk during the } \\
\text { interval }\left(r_{x}\right)\end{array}$ & $\begin{array}{c}\text { Deaths during } \\
\text { the interval }\left(d_{x}\right)\end{array}$ & $\begin{array}{c}\text { Death rate } \\
\text { during the } \\
\text { interval }\left(q_{x}\right)\end{array}$ & $\begin{array}{c}\text { Survival rate } \\
\text { during the } \\
\text { interval }\left(p_{x}\right)\end{array}$ & $\begin{array}{c}\text { Cumulative survival } \\
\text { rate up to end of } \\
\text { interval } S\left(t_{x}\right)\end{array}$ \\
\hline$(0-6)$ & 48 & 0 & 48 & 4 & 0.083 & 0.917 & 0.917 \\
$(6-12)$ & 44 & 3 & 42.5 & 6 & 0.141 & 0.859 & 0.787 \\
\hline
\end{tabular}

Where: $\left(r_{x}=l_{x}-w_{x} / 2\right),\left(q_{x}=d_{x} / r_{x}\right)$ e $\left(p_{x}=1-q_{x}\right)$.

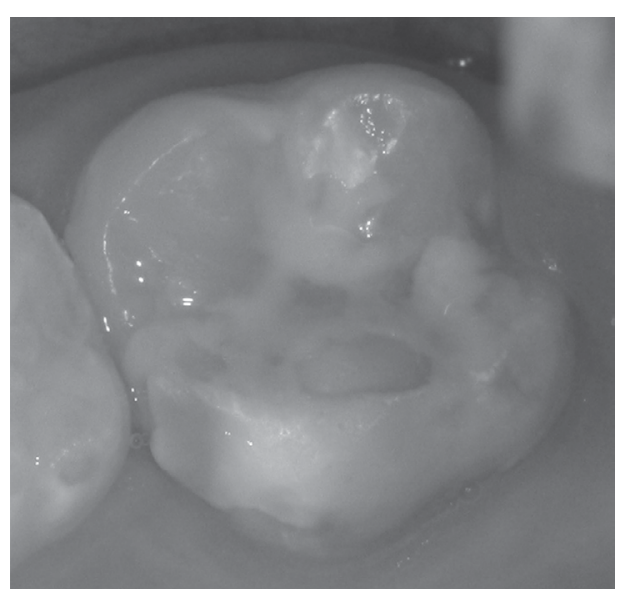

Figure 1. Atypical protective satisfactory restoration at 12-month evaluation.

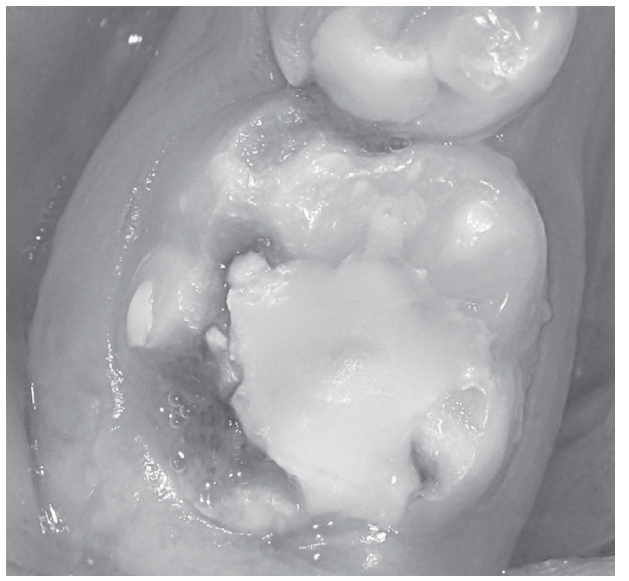

Figure 2. Tooth breakdown and protective material at 6-month evaluation. 
Table 3. Number and percentage of teeth according to caries experience, retreatments and faces restored at baseline, associated with the failed restoration.

\begin{tabular}{|c|c|c|c|c|}
\hline Months & Restoration (N) & Caries Experience $\mathrm{n}(\%)$ & $p^{*}$ & $\operatorname{RR}(95 \% \mathrm{Cl})$ \\
\hline \multirow[t]{2}{*}{6} & Satisfactory (44) & $28(63.6)$ & 0.624 & $1.27(0.46-3.47)$ \\
\hline & Unsatisfactory (4) & $2(50.0)$ & & \\
\hline \multirow[t]{3}{*}{12} & Satisfactory (38) & $22(57.8)$ & $0.380^{* *}$ & $0.69(0.44-1.08)$ \\
\hline & Unsatisfactory (6) & $5(83.3)$ & & \\
\hline & & Retreatments n (\%) & $p^{*}$ & $\operatorname{RR}(95 \% \mathrm{Cl})$ \\
\hline \multirow[t]{2}{*}{6} & Satisfactory (44) & $12(27.2)$ & 0.569 & $0.54(0.18-1.62)$ \\
\hline & Unsatisfactory (4) & $2(50.0)$ & & \\
\hline \multirow[t]{3}{*}{12} & Satisfactory (38) & $9(23.6)$ & 0.630 & $0.71(0.20-2.52)$ \\
\hline & Unsatisfactory (6) & 2 (33.3) & & \\
\hline & & Two or more faces restored $\mathrm{n}(\%)$ & $p^{*}$ & $\mathrm{RR}(95 \% \mathrm{Cl})$ \\
\hline \multirow[t]{2}{*}{6} & Satisfactory (44) & $20(45.4)$ & $0.338 * *$ & $0.60(0.31-1.16)$ \\
\hline & Unsatisfactory (4) & $3(75.0)$ & & \\
\hline \multirow[t]{2}{*}{12} & Satisfactory (38) & $15(39.4)$ & $0.337^{* *}$ & $0.59(0.29-1.17)$ \\
\hline & Unsatisfactory (6) & $4(66.6)$ & & \\
\hline
\end{tabular}

*Fisher's Exact Test.

** Statistically significant.

rate of the structure, and consequent exacerbation of the symptoms. . $^{15,24}$

A very useful 6-step management approach for MIH has been proposed ${ }^{25}$ and was followed in this study: risk identification, early diagnosis, remineralization, prevention of dental caries and post eruptive enamel breakdown, restorations or extractions, and maintenance.

The indications for treatment of teeth affected by MIH vary according to the degree of severity. Treatment includes preventive procedures provided only in cases where there is no structural loss, and conservative or invasive restorations when the affected area must be removed..$^{15}$ In the present study, we observed that new breakdowns occurred even when a conservative treatment was applied, consisting of fluoride varnish application and glass ionomer cement restoration. However, these breakdowns occurred at low rates, a finding that leads us to infer that complete or premature removal of the affected area is not justified. . $^{16,17,18}$

Glass ionomer cement facilitates the mineralization process and protects the remaining structures from tooth caries lesion formation and tooth sensitivity. In addition, because glass ionomer cement has a coefficient of thermal expansion similar to the tooth structure, it is a good choice for restorations of teeth with MIH. However, the deficient mechanical properties of glass ionomer cement, ${ }^{26}$ associated with the disorganized structure of $\mathrm{MIH},{ }^{27}$ can result in the reduced longevity of GIC restorations. The pore incorporation inside the material, resulting from its manual manipulation and insertion, is also a factor to bear in mind, since it can alter some GIC properties. ${ }^{28}$ Nevertheless, the likelihood of maintaining complete protection throughout 12 months was $78 \%$. Studies with longer observation periods are needed to confirm the success of the treatment.

According to the literature, Ketac ${ }^{\mathrm{TM}}$ Molar Easymix (3M ESPE, São Paulo, Brazil) offers good performance in regard to compressive strength and solubility, and better values than the other materials in regard to early flexural strength and acid erosion. ${ }^{29}$ Ketac $^{\mathrm{TM}}$ Molar Easymix (3M ESPE, São Paulo, Brazil) high-viscous glass ionomer is widely used in atraumatic restorative techniques, and presents cumulative single-surface survival rates in permanent teeth, reported at 86.5 and $80.9 \%$ after 1 and 2 years, respectively. ${ }^{30}$ This data is similar to that found in this study for teeth with MIH.

School-age patients naturally find it difficult to collaborate in studies of this type. This factor, together with the clinical features of MIH, which include exacerbated sensitivity and difficulty in anesthetizing, can impede proper professional action. 
Therefore, conservative treatment is recommended mostly until younger children become mature enough to understand and cooperate with more complex treatment and rehabilitation procedures.

\section{Conclusions}

The probability of maintaining tooth structure integrity in molars affected by $\mathrm{MIH}$ and restored with

\section{References}

1. Weerheijm KL, Duggal M, Mejàre I, Papagiannoulis L, Koch G, Martens LC, et al. Judgement criteria for molar incisor hypomineralisation (MIH) in epidemiologic studies: a summary of the European meeting on MIH held in Athens, 2003. Eur J Paediatr Dent. 2003;4(3):110-3. PubMed PMID: 14529329.

2. Jedeon K, De la Dure-Molla M, Brookes SJ, Loiodice S, Marciano C, Kirkham J, et al. Enamel defects reflect perinatal exposure to bisphenol A. Am J Pathol. 2013;183(1):108-18. doi: 10.1016/j.ajpath.2013.04.004. PubMed PMID: 23764278; PubMed Central PMCID: PMCPMC3703547.

3. Fagrell TG, Salmon P, Melin L, Norén JG. Onset of molar incisor hypomineralization (MIH). Swed Dent J. 2013;37(2):61-70. PubMed PMID: 23957140.

4. Jeremias F, Koruyucu M, Küchler EC, Bayram M, Tuna EB, Deeley K, et al. Genes expressed in dental enamel development are associated with molar-incisor hypomineralization. Arch Oral Biol. 2013;58(10):1434-42. doi: 10.1016/j.archoralbio.2013.05.005. PubMed PMID: 23790503; PubMed Central PMCID: PMCPMC3769477.

5. Kühnisch J, Thiering E, Heitmüller D, Tiesler CM, Grallert $\mathrm{H}$, Heinrich-Weltzien R, et al. Genome-wide association study (GWAS) for molar-incisor hypomineralization (MIH). Clin Oral Investig. 2014;18(2):677-82. doi: 10.1007/s00784-013-1054-8. PubMed PMID: 23918034.

6. Souza JF, Jeremias F, Costa-Silva CM, Santos-Pinto L, Zuanon AC, Cordeiro RC. Aetiology of molar-incisor hypomineralisation (MIH) in Brazilian children. Eur Arch Paediatr Dent. 2013. doi: 10.1007/s40368-013-0054-3. PubMed PMID: 23797926.

7. Jalevik B. Prevalence and Diagnosis of Molar-Incisor-Hypomineralisation (MIH): a systematic review. Eur Arch Paediatr Dent. 2010;11(2):59-64. Epub 2010 Apr 21. doi: 09.58 [pii]. PubMed PMID: 20403299.

8. Weerheijm KL. Molar incisor hypomineralisation (MIH). Eur J Paediatr Dent. 2003;4(3):114-20. PubMed PMID: 14529330.

9. Jalevik B, Noren JG. Enamel hypomineralization of permanent first molars: a morphological study and survey of possible aetiological factors. Int J Paediatr Dent. 2000;10(4):278-89. Epub 2001 Apr 20. PubMed PMID: 11310241.

10. Weerheijm KL, Duggal M, Mejare I, Papagiannoulis L, Koch G, Martens LC, et al. Judgement criteria for molar incisor
GIC was found to be high, mainly in single-surface tooth restorations. Considering this finding, together with the ages of the children and the developmental stage of the affected teeth, it can be concluded that invasive treatment - complete removal of the affected area - should be postponed until the child is mature enough to understand and cooperate with more complex rehabilitation and treatment procedures.

hypomineralisation (MIH) in epidemiologic studies: a summary of the European meeting on MIH held in Athens, 2003. Eur J Paediatr Dent. 2003;4(3):110-3. Epub 2003 Oct 8. PubMed PMID: 14529329.

11. Jalevik B, Klingberg G, Barregard L, Noren JG. The prevalence of demarcated opacities in permanent first molars in a group of Swedish children. Acta Odontol Scand. 2001;59(5):255-60. Epub 2001 Oct 30. PubMed PMID: 11680642.

12. Weerheijm KL. Molar incisor hypomineralization (MIH): clinical presentation, aetiology and management. Dent Update. 2004;31(1):9-12. Epub 2004 Mar 6. PubMed PMID: 15000003.

13. Fagrell TG, Dietz W, Jälevik B, Norén JG. Chemical, mechanical and morphological properties of hypomineralized enamel of permanent first molars. Acta Odontol Scand. 2010;68(4):215-22. doi: 10.3109/00016351003752395. PubMed PMID: 20392131.

14. Costa-Silva CM, Ambrosano GM, Jeremias F, Souza JF, Mialhe FL. Increase in severity of molar-incisor hypomineralization and its relationship with the colour of enamel opacity: a prospective cohortstudy. Int J Paediatr Dent. 2011;21(5):333-41. Epub 2011 Apr 8. doi: 10.1111/j.1365-263X.2011.01128.x. PubMed PMID: 21470321.

15. Lygidakis NA. Treatment modalities in children with teeth affected by molar-incisor enamel hypomineralisation (MIH): a systematic review. Eur Arch Paediatr Dent. 2010;11(2):65-74. PubMed PMID: 20403300.

16. Takahashi K, Correia AS, Cunha RF. Molar incisor hypomineralization. J Clin Pediatr Dent. 2009;33(3):193-7. Epub 2009 May 30. PubMed PMID: 19476090.

17. Lygidakis NA, Chaliasou A, Siounas G. Evaluation of composite restorations in hypomineralised permanent molars: a four year clinical study. Eur J Paediatr Dent. 2003;4(3):143-8. Epub 2003 Oct 8. PubMed PMID: 14529336.

18. Zagdwon AM, Fayle SA, Pollard MA. A prospective clinical trial comparing preformed metal crowns and cast restorations for defective first permanent molars. Eur J Paediatr Dent. 2003;4(3):138-42. Epub 2003 Oct 8. PubMed PMID: 14529335.

19. Jeremias F, Souza JF, Silva CM, Cordeiro RC, Zuanon AC, Santos-Pinto L. Dental caries experience and Molar-Incisor Hypomineralization. Acta Odontol Scand. 2013; 71(3-4):870-6. Epub 2013 Jan 28. PubMed PMID: 23351220. 
20. World Health Organization. Oral Health Surveys: basic methods. 4th ed. Geneva: World Health Organization; 1997. $67 \mathrm{p}$.

21. Cvar JF, Ryge G. Reprint of criteria for the clinical evaluation of dental restorative materials. 1971. Clin Oral Investig. 2005;9(4):215-32. doi: 10.1007/s00784-005-0018-z. PubMed PMID: 16315023.

22. Jälevik B, Klingberg GA. Dental treatment, dental fear and behaviour management problems in children with severe enamel hypomineralization of their permanent first molars. Int J Paediatr Dent. 2002;12(1):24-32. PubMed PMID: 11853245.

23. Leppäniemi A, Lukinmaa PL, Alaluusua S. Nonfluoride hypomineralizations in the permanent first molars and their impact on the treatment need. Caries Res. 2001;35(1):36-40. doi: 47428. PubMed PMID: 11125194.

24. Lygidakis NA, Wong F, Jälevik B, Vierrou AM, Alaluusua S, Espelid I. Best Clinical Practice Guidance for clinicians dealing with children presenting with Molar-Incisor-Hypomineralisation (MIH): An EAPD Policy Document. Eur Arch Paediatr Dent. 2010;11(2):75-81. PubMed PMID: 20403301.

25. William V, Messer LB, Burrow MF. Molar incisor hypomineralization: review and recommendations for clinical management. Pediatr Dent. 2006;28(3):224-32. PubMed PMID: 16805354.
26. Lygidakis NA, Wong F, Jalevik B, Vierrou AM, Alaluusua S, Espelid I. Best Clinical Practice Guidance for clinicians dealing with children presenting with Molar-Incisor-Hypomineralisation (MIH): an EAPD Policy Document. Eur Arch Paediatr Dent. 2010;11(2):75-81. Epub 2010 Apr 21. doi: 10.02 [pii]. PubMed PMID: 20403301.

27. Mahoney E, Ismail FS, Kilpatrick N, Swain M. Mechanical properties across hypomineralized/hypoplastic enamel of first permanent molar teeth. Eur J Oral Sci. 2004;112(6):497-502. Epub 2004 Nov 25. doi: EOS162 [pii] 10.1111/j.1600-0722.2004.00162.x. PubMed PMID: 15560832.

28. Mata M, Santos-Pinto L, Cilense Zuanon AC. Influences of the insertion method in glass ionomer cement porosity. Microsc Res Tech. 2012;75(5):667-70. doi: 10.1002/jemt.21109. PubMed PMID: 22298315.

29. Peez R, Frank S. The physical-mechanical performance of the new Ketac Molar Easymix compared to commercially available glass ionomer restoratives. J Dent. 2006;34(8):582-7. doi: 10.1016/j.jdent.2004.12.009. PubMed PMID: 16581174.

30. Luengas-Quintero E, Frencken JE, Muñúzuri-Hernández JA, Mulder J. The atraumatic restorative treatment (ART) strategy in Mexico: two-years follow up of ART sealants and restorations. BMC Oral Health. 2013;13:42. doi: 10.1186/1472-6831-13-42. PubMed PMID: 24010679; PubMed Central PMCID: PMCPMC3847480. 